\title{
Ultrasonic velocity variation of Ti6Al4V Ti-alloy bars under conventional forging combined with triple heat treatment
}

\author{
Feixiao Han, Fengqi Hou, Xiaoping Sun, Zhixia Liu, Yonggang He, KaixuanWang \\ Western Superconducting Technologies Co., Ltd, Xi'an, 710018, China
}

\begin{abstract}
In this paper, the microstructure evolution and ultrasonic velocity variation of Ti6Al4V Ti-alloy bars under different conventional forging deformation degrees and triple heat treatment were investigated, it was found that the the orientation of microstructure is the main factor influencing the ultrasonic velocity. Meanwhile, taking the ultrasonic velocity as target, the ultrasonic velocity variation under given conventional forging process combined with different triple heat treatment conditions (heating temperatures, holding time) were revealed, it was found that the $\alpha-\beta$ phase ratio, the volume fraction and morphology of equiaxed $a_{\mathrm{p}}$ and lamellar $a_{\mathrm{s}}$ are also influencing the ultrasonic velocity.
\end{abstract}

Keywords: Ti6Al4V Ti-alloy, Conventional forging, Triple heat treatment, Ultrasonic velocity

\section{Introduction}

Ti6Al4V alloy is a typical $(\alpha+\beta)$ titanium alloy, possessing excellent comprehensive properties such as high strength, high specific strength and good creep performance at high temperature, is extensively used to manufacture structural components in aerospace field, such as joints and frames ${ }^{[1]}$.As a conventional nondestructive testing method, ultrasonic testing applies a variety of physical and chemical phenomena to test without damaging the materials, so as to evaluate the physical properties, state and internal structure of the materials, and to determine whether or not they are qualified. By measuring the ultrasonic velocity of the material, the microstructure and properties of the material can be detected and evaluated ${ }^{[2-3]}$.

Ultrasonic velocity is a basic physical quantity describing the propagation characteristics of ultrasonic wave in the medium, which is closely related to the material and the bonding force between material atoms and the atomic spacing. Meanwhile, to some extent, the properties of the material are determined by the microstructure of the alloy, so there is a certain relationship between the ultrasonic velocity value and the microstructure [4-7]。 The purpose of the present paper is to investigate the microstructure evolution and ultrasonic velocity variation of Ti6Al4V Ti-alloy bars under different conventional forging deformation degrees, and to reveal the effect of triple heat treatment conditions on the ultrasonic velocity variation.

\section{Materials and methods}

\subsection{Starting materials}

The Ti6Al4V Ti-alloy used in the experiments was from Western Superconducting Technologies Co., Ltd with a transus $\beta$ temperature of $985-990^{\circ} \mathrm{C}$, its chemical composition is listed in Table 1. The microstructure of as-received material consists of above $60 \%$ equiaxed $a_{\mathrm{p}}$ and transformation $\beta$ matrix, as shown in Fig. 1.

Table 1. Chemical composition of Ti6Al4V Ti-alloy

\begin{tabular}{|c|c|c|c|c|c|c|c|c|}
\hline Element & $\mathrm{Al}$ & $\mathrm{V}$ & $\mathrm{C}$ & $\mathrm{Fe}$ & $\mathrm{O}$ & $\mathrm{N}$ & $\mathrm{H}$ & $\mathrm{Ti}$ \\
\hline $\begin{array}{c}\text { Nominal } \\
\text { composition/\% }\end{array}$ & $6.50 \sim 6.60$ & $4.28 \sim 4.32$ & $<0.08$ & 0.15 & $<0.12$ & $<0.05$ & 0.001 & Balance \\
\hline
\end{tabular}




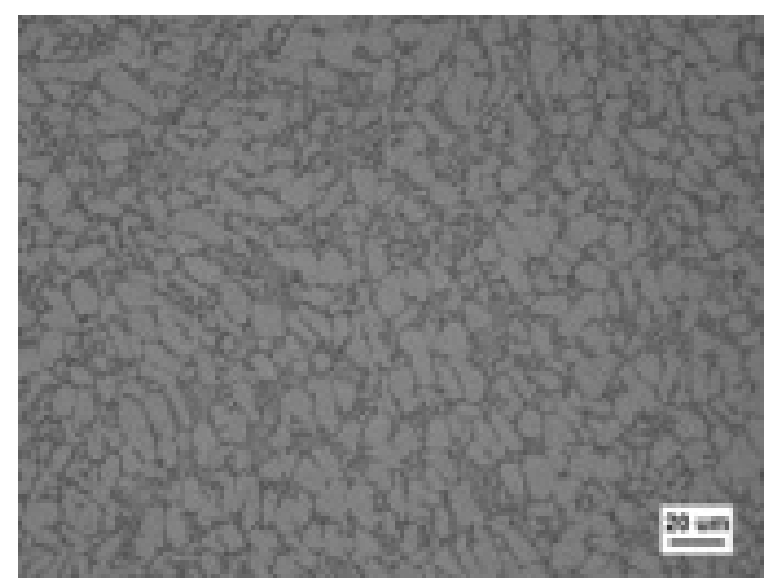

Fig 1. Original microstructure of Ti6Al4V Ti-alloy

\subsection{Experimental procedure}

The bars with a diameter of $95.0 \mathrm{~mm}$ were cut from the as-received bars. The conventional forging process was conducted on a GFM precision forging machine. The ultrasonic velocity was measured on a CL400 ultrasonic pulse reflector, as shown in Fig. 2.

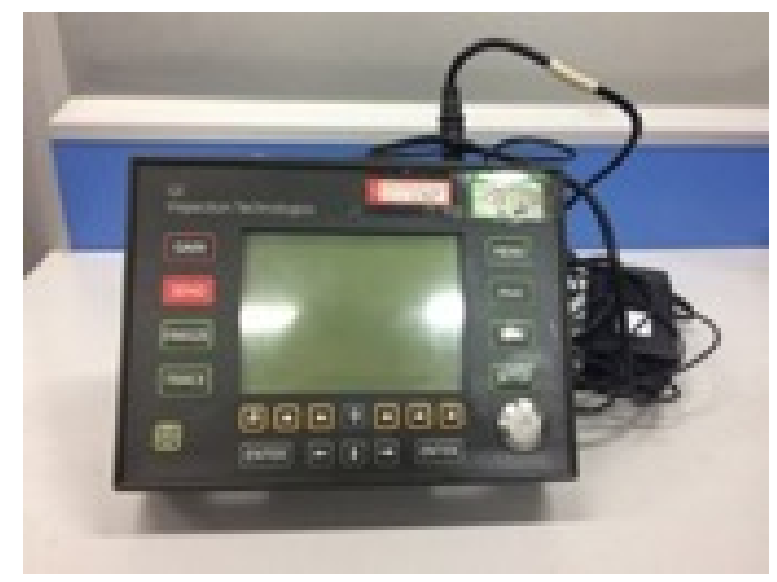

Fig 2. CL400 ultrasonic pulse reflector

In conventional forging process, forging deformation degree of $75 \%$ and $90 \%$ was considered. In subsequent triple heat treatment two heat treatment conditions (heating temperature, holding time) were considered, in detail, solution temperature of $950-970^{\circ} \mathrm{C}$, ageing temperature of $500-600^{\circ} \mathrm{C}$, ageing holding time of $1-3 \mathrm{~h}$. The ultrasonic velocity value was taken as evaluation index to investigate the effect of conventional forging deformation degree and heat treatment conditions, so as to reveal which factor affecting the ultrasonic velocity most.

The bars were heated to the conventional forging temperature at a heating rate of $10^{\circ} \mathrm{C} / \mathrm{min}$ and held for 70 min to achieve thermal equilibrium and then forged. A section of $85.0 \mathrm{~mm}$ specimen was cut off from the conventional forging bar, and then turned two end faces. The ultrasonic velocity was measured on the end faces with three times and the average values are taken, the measurement uncertainty on velocity value is $0.2 \%$. The specimens were axially sectioned and prepared for metallographic observation by an optical microscope.

\section{The microstructure evolution and ultrasonic velocity variation under different forging degrees.}

Fig. 3 shows the microstructure of original Ti6Al4V Ti-alloy bar with a diameter of $95.0 \mathrm{~mm}$. It can be found that the transverse equiaxed $a_{p}$ was small and fine, while the longitudinal microstructure has a certain orientation but was not obvious. Fig. 4 shows the microstructure in different directions of dia. $45.0 \mathrm{~mm}$ and dia. $30.0 \mathrm{~mm}$ bars after forging at $940{ }^{\circ} \mathrm{C}$, the corresponding ultrasonic velocity was shown in Table 2. It was obvious that longitudinal microstructure of two specifications has processing orientation, which was growing stronger as the forging deformation degree increased from $75 \%$ of dia. $45.0 \mathrm{~mm}$ to $90 \%$ of dia. $30 . \mathrm{mm}$, the primary equiaxed $a_{p}$ was elongated and even broken. Meanwhile, the longitudinal ultrasonic velocity decreased from $6120 \mathrm{~m} / \mathrm{s}$ of original dia. $95.0 \mathrm{~mm}$ to $6080 \mathrm{~m} / \mathrm{s}$ of dia. $30.0 \mathrm{~mm}$, as shown in Fig. $4(\mathrm{a}$, c). On the contrary, the transverse ultrasonic velocity increased from $6230 \mathrm{~m} / \mathrm{s}$ of original dia. $95.0 \mathrm{~mm}$ to $6305 \mathrm{~m} / \mathrm{s}$ of dia. $30.0 \mathrm{~mm}$. In addition, the difference of ultrasonic velocity between transverse and longitudinal directions increases as forging deformation degree 
increasing. The original difference of dia. $95.0 \mathrm{~mm}$ was $110 \mathrm{~m} / \mathrm{s}$, however, the difference increased to $155 \mathrm{~m} / \mathrm{s}$ and $225 \mathrm{~m} / \mathrm{s}$ after the forging deformation degree increased to $75 \%$ and $90 \%$ respectively.

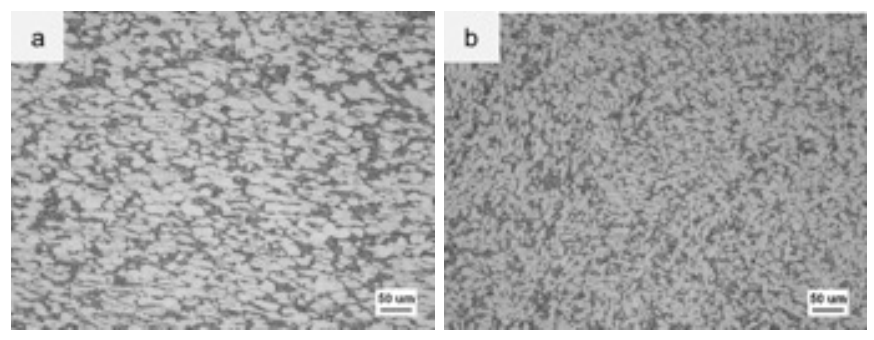

Fig 3. Microstructure in different directions of the original dia.95mm bar: (a) $\mathrm{L}$ direction; (b) T direction
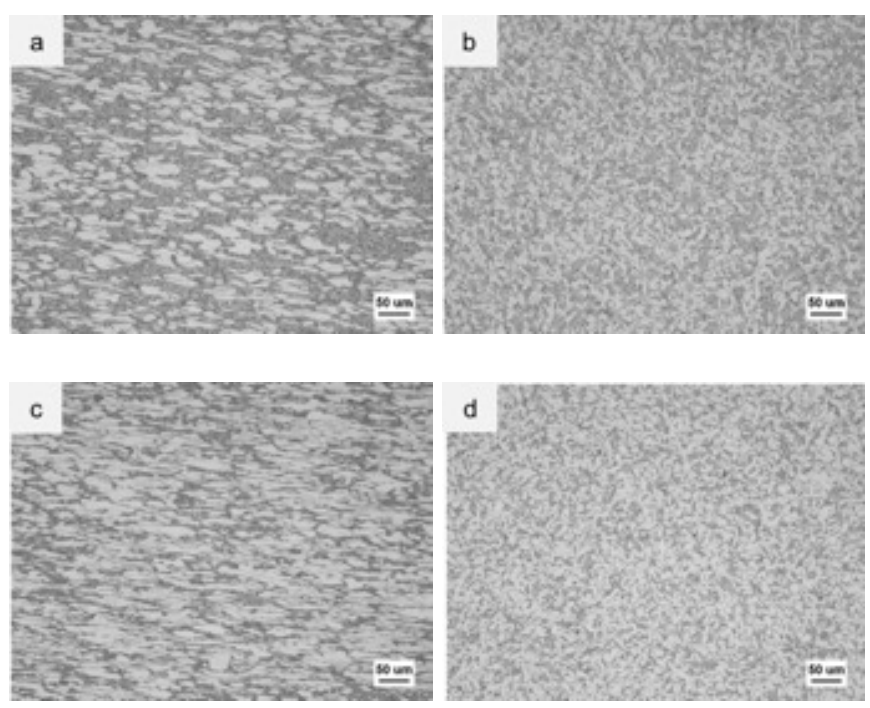

Fig 4. Microstructure of dia. $45.0 \mathrm{~mm}$ and dia. $30.0 \mathrm{~mm}$ bars in different directions after forging :

(a) dia. 45.0mm/L direction; (b) dia. $45.0 \mathrm{~mm} / \mathrm{T}$ direction; (c) dia. $30.0 \mathrm{~mm} / \mathrm{L}$ direction; (d) dia. $30.0 \mathrm{~mm} / \mathrm{T}$ direction

Table 2. Transverse and longitudinal velocity under different forging degrees

\begin{tabular}{|c|c|c|c|c|}
\hline $\begin{array}{c}\text { Heating temperature } \\
{ }^{\circ} \mathrm{C}\end{array}$ & Diameter & Forging degrees & Transverse velocity & Longitudinal velocity \\
\hline$/$ & $\mathrm{mm}$ & $\%$ & $\mathrm{~m} / \mathrm{s}$ & $\mathrm{m} / \mathrm{s}$ \\
\hline \multirow{2}{*}{940} & $\Phi 95$ & 0 & 6230 & 6120 \\
\cline { 2 - 5 } & $\Phi 45$ & 75 & 6255 & 6100 \\
\hline
\end{tabular}

In an infinite solid medium, the longitudinal ultrasonic velocity can be described by the following formula:

$$
v=\sqrt{\frac{E(1-\sigma)}{\rho(1+\sigma)(1-2 \sigma)}}
$$

In the above formula, $\mathrm{E}$ is the elastic modulus $\left(\mathrm{N} / \mathrm{m}^{2}\right), \rho$ is the medium density $\left(\mathrm{kg} / \mathrm{m}^{3}\right)$, and $\sigma$ is the poisson's ratio. For solids, the $\sigma$ is usually in the range of $0 \sim 0.5$. Therefore, for Ti6Al4V Ti-alloy, when the composition was determined, the main cause for the ultrasonic velocity variation of forging bar was the change of elastic modulus caused by microstructure under different processes, while the elastic modulus was mainly affected by the plastic deformation, crystal structure and phase transformation. After large plastic deformation, obvious processing texture will emerge in metal materials. Due to the existence of processing texture, the properties of bars in different directions will be different. Meanwhile, there is a big difference in the elastic modulus between the longitudinal and transverse direction ${ }^{[8]}$, thus leading to a big difference in the ultrasonic velocity.

\section{The microstructure evolution and ultrasonic velocity variation under triple heat treatment}

Fig. 5 shows the microstructure of dia. $45.0 \mathrm{~mm}$ forging bar after $730^{\circ} \mathrm{C} / 1 \mathrm{~h}, \mathrm{AC}, 950^{\circ} \mathrm{C} / 1 \mathrm{~h}, \mathrm{AC}+730^{\circ} \mathrm{C} / 1 \mathrm{~h}, \mathrm{AC}$ and $950^{\circ} \mathrm{C} / 1 \mathrm{~h}$, $\mathrm{AC}+730^{\circ} \mathrm{C} / 1 \mathrm{~h}, \mathrm{AC}+550^{\circ} \mathrm{C} / 2 \mathrm{~h}, \mathrm{AC}$ heat treatment, the corresponding ultrasonic velocity was shown in Table 3 . It can be found that 
after $730^{\circ} \mathrm{C} / 1 \mathrm{~h}, \mathrm{AC}$ common annealing, the longitudinal microstructure did not change obviously compared to the original thermal-forging state ( $R$ state), the orientation of microstructure and $\alpha-\beta$ ratio changed little as shown in Fig. 5(a, b). The ultrasonic velocity was consistent with the $\mathrm{R}$ state. However, after $950^{\circ} \mathrm{C} / 1 \mathrm{~h}, \mathrm{AC}+730^{\circ} \mathrm{C} / 1 \mathrm{~h}, \mathrm{AC}$ two-step heat treatment, the ultrasonic velocity increased significantly, from $6110 \mathrm{~m} / \mathrm{s}$ in R state to $6165 \mathrm{~m} / \mathrm{s}$. This was because the volume fraction of equiaxed $a_{p}$ decreased significantly as well as the orientation due to the $a \rightarrow \beta$ phase transformation and recrystallization at $950^{\circ} \mathrm{C}$ high temperature, as shown in Fig. 5 (c). After $950^{\circ} \mathrm{C} / 1 \mathrm{~h}, \mathrm{AC}+730^{\circ} \mathrm{C} / 1 \mathrm{~h}, \mathrm{AC}+550^{\circ} \mathrm{C} / 2 \mathrm{~h}$, AC triple heat treatment, the ultrasonic velocity increase further to $6175 \mathrm{~m} / \mathrm{s}$. The orientation of microstructure was barely changed, but the volume fraction and thickness of secondary lamellar $a_{\mathrm{s}}$ increased, as shown in Fig. 5(d). This was because in two-phase Ti-alloy, the atomic density of $\mathrm{a}-\mathrm{Ti}$ (HCP) was higher than that of $\beta-\mathrm{Ti}$ (BCC, the atomic density was 0.68). Therefore, the elastic modulus of a phase was higher than that of $\beta$ phase, the ultrasonic wave propagated faster in a phase.
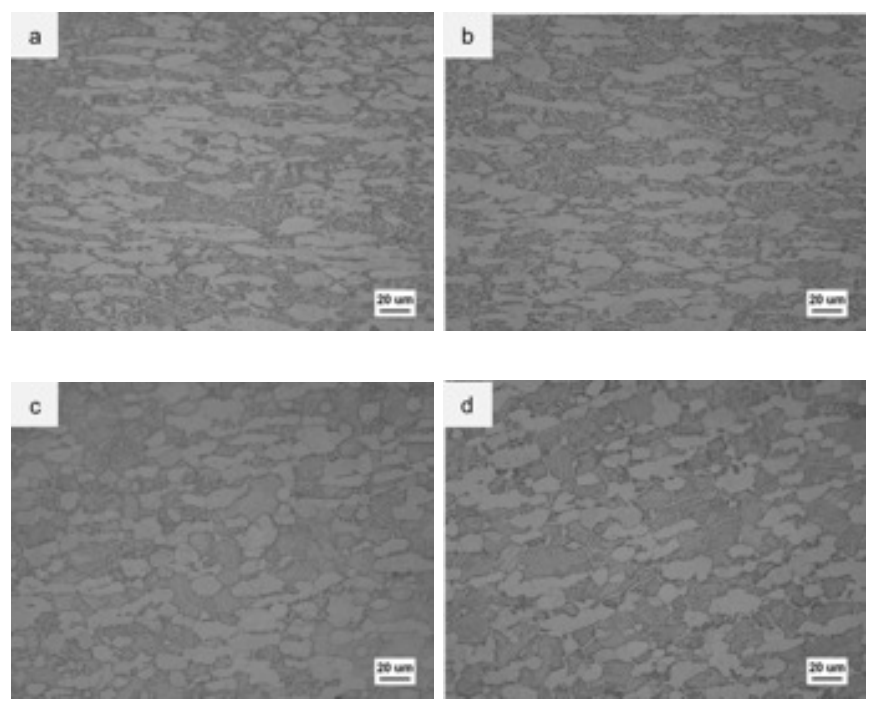

Fig 5. Microstructure of dia. $45.0 \mathrm{~mm}$ bar after heated at different heat treatments : (a) Original microstructure;

(b) $730^{\circ} \mathrm{C} / 1 \mathrm{~h}, \mathrm{AC}$; (c) $950^{\circ} \mathrm{C} / 1 \mathrm{~h}, \mathrm{AC}+730^{\circ} \mathrm{C} / 1 \mathrm{~h}, \mathrm{AC}$; (d) $950^{\circ} \mathrm{C} / 1 \mathrm{~h}, \mathrm{AC}+730^{\circ} \mathrm{C} / 1 \mathrm{~h}, \mathrm{AC}+550^{\circ} \mathrm{C} / 2 \mathrm{~h}, \mathrm{AC}$

Table 3. Microstructure and velocity of dia. $45 \mathrm{~mm}$ bar under different heat treatments

\begin{tabular}{|c|c|c|}
\hline No. & Heat treatment & Longitudinal velocity $/(\mathrm{m} / \mathrm{s})$ \\
\hline 1 & Thermal-forging state (R state) & 6110 \\
\hline 2 & $730^{\circ} \mathrm{C} / 1 \mathrm{~h}, \mathrm{AC}$ & 6115 \\
\hline 3 & $950^{\circ} \mathrm{C} / 1 \mathrm{~h}, \mathrm{AC}+730^{\circ} \mathrm{C} / 1 \mathrm{~h}, \mathrm{AC}$ & 6165 \\
\hline 4 & $950^{\circ} \mathrm{C} / 1 \mathrm{~h}, \mathrm{AC}+730^{\circ} \mathrm{C} / 1 \mathrm{~h}, \mathrm{AC}+550^{\circ} \mathrm{C} / 2 \mathrm{~h}, \mathrm{AC}$ & 6175 \\
\hline
\end{tabular}

Apparently, given the conventional forging process, the ultrasonic velocity of Ti6Al4V forging bars varied significantly under different triple heat treatments. Therefore, it was necessary to study the microstructure evolution and ultrasonic velocity variation under different triple heat treatment conditions, so as to provide a reference for adjusting the ultrasonic velocity in different directions of forging bars.

\subsection{The microstructure evolution and ultrasonic velocity variation under different solution temperatures.}

Fig. 6 shows the microstructure of Ti6Al4V dia. $45.0 \mathrm{~mm}$ forging bar heated at different solution temperatures of $950^{\circ} \mathrm{C}, 960^{\circ} \mathrm{C}$ and $970^{\circ} \mathrm{C}$ and subsequent $730^{\circ} \mathrm{C} / 1 \mathrm{~h}, \mathrm{AC}+550^{\circ} \mathrm{C} / 2 \mathrm{~h}, \mathrm{AC}$ heat treatment, the corresponding ultrasonic velocity was $6175 \mathrm{~m} / \mathrm{s}, 6190 \mathrm{~m} / \mathrm{s}$ and $6208 \mathrm{~m} / \mathrm{s}$ respectively. As the solution temperature increasing from $950^{\circ} \mathrm{C}$ to $960^{\circ} \mathrm{C}$, equiaxed $a_{\mathrm{p}}$ will transform into high-temperature $\beta$ phase and its volume fraction will reduce. Meanwhile, the orientation of microstructure decreased because of recrystallization at high temperature, the ultrasonic increased from $6175 \mathrm{~m} / \mathrm{s}$ to $6190 \mathrm{~m} / \mathrm{s}$. As the solution temperature increasing further, equiaxed $a_{p}$ decreased faster, and there is basically no obvious orientation or processing texture, as shown in Fig. 6(c). However, for a given Ti-alloy the content of a stable element is certain, when the volume fraction of equiaxed $a_{p}$ decreased, that of lamellar $a_{s}$ will increase [9]. Thus the ultrasonic velocity increased further, from $6190 \mathrm{~m} / \mathrm{s}$ to $6208 \mathrm{~m} / \mathrm{s}$. 

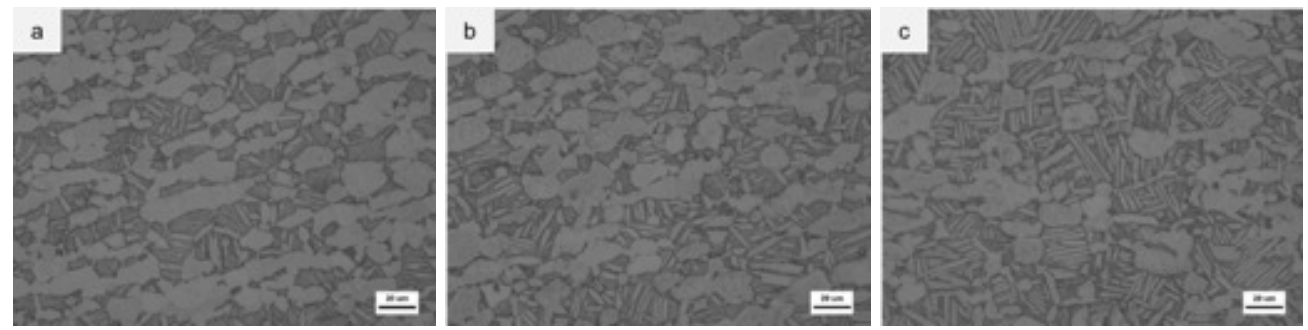

Fig 6. Microstructure after heated at different solution temperatures and $730^{\circ} \mathrm{C} / 1 \mathrm{~h}, \mathrm{AC}+550^{\circ} \mathrm{C} / 2 \mathrm{~h}, \mathrm{AC}$ :

(a) $950^{\circ} \mathrm{C} / 1 \mathrm{~h} / \mathrm{AC}$; (b) $960^{\circ} \mathrm{C} / 1 \mathrm{~h} / \mathrm{AC}$; (c) $970^{\circ} \mathrm{C} / 1 \mathrm{~h} / \mathrm{AC}$

\subsection{The microstructure evolution and ultrasonic velocity variation under different ageing temperatures.}

Fig. 7 shows the microstructure of dia. $45.0 \mathrm{~mm}$ forging bar heated at $960^{\circ} \mathrm{C} / 1 \mathrm{~h}, \mathrm{AC}+730^{\circ} \mathrm{C} / 1 \mathrm{~h}, \mathrm{AC}$ and different ageing temperatures of $500^{\circ} \mathrm{C}, 550^{\circ} \mathrm{C}$ and $600^{\circ} \mathrm{C}$ heat treatment, the corresponding ultrasonic velocity was $6200 \mathrm{~m} / \mathrm{s}, 6190 \mathrm{~m} / \mathrm{s}$ and $6178 \mathrm{~m} / \mathrm{s}$ respectively. It can be found that as ageing temperature increasing, the orientation of microstructure changed little, but the volume fraction and thickness of secondary lamellar $a_{s}$ decreased significantly. As mentioned above, the ultrasonic wave propagated faster in a phase compared to $\beta$ phase, the ultrasonic velocity decreased as the volume fraction of $a$ phase decreased.
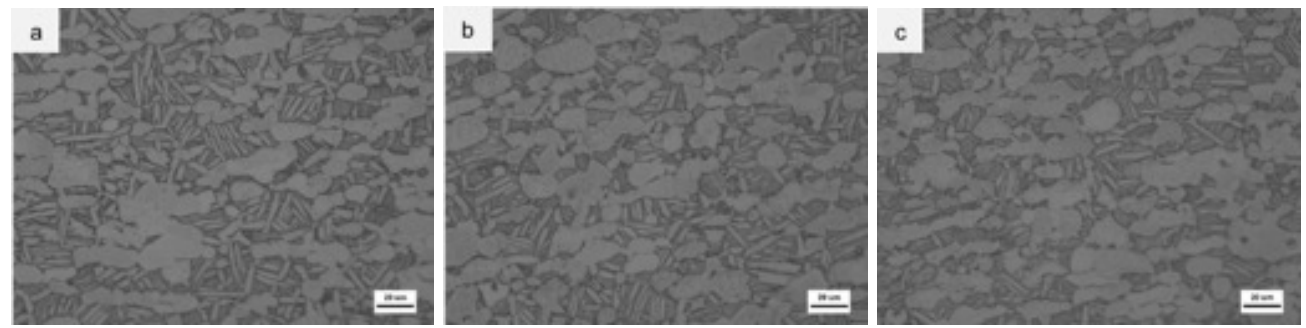

Fig 7. Microstructure after heated at $960^{\circ} \mathrm{C} / 1 \mathrm{~h}, \mathrm{AC}+730^{\circ} \mathrm{C} / 1 \mathrm{~h}, \mathrm{AC}$ and different ageing temperatures heat treatment: (a) $500^{\circ} \mathrm{C} / 2 \mathrm{~h} / \mathrm{AC} ;(\mathrm{b})$ $550^{\circ} \mathrm{C} / 2 \mathrm{~h} / \mathrm{AC}$; (c) $600^{\circ} \mathrm{C} / 2 \mathrm{~h} / \mathrm{AC}$

\subsection{The microstructure evolution and ultrasonic velocity variation under different ageing holding time.}

Fig. 8 shows the microstructure of dia. $45 \mathrm{~mm}$ forging bar heated at $960^{\circ} \mathrm{C} / 1 \mathrm{~h}, \mathrm{AC}+730^{\circ} \mathrm{C} / 1 \mathrm{~h}, \mathrm{AC}$ and different ageing holding time of $1 \mathrm{~h}, 2 \mathrm{~h}$ and $3 \mathrm{~h}$ heat treatment, the corresponding ultrasonic velocity was $6186 \mathrm{~m} / \mathrm{s}, 6190 \mathrm{~m} / \mathrm{s}$ and $6195 \mathrm{~m} / \mathrm{s}$ respectively. As the ageing holding time increasing, the lamellar $a_{s}$ precipitated from $\beta$ transformed matrix gradually, leading to an increase in the volume fraction and thickness of $\alpha_{s}$, the ultrasonic velocity increased from $6186 \mathrm{~m} / \mathrm{s}$ to $6195 \mathrm{~m} / \mathrm{s}$, but the extent of increase was modest.
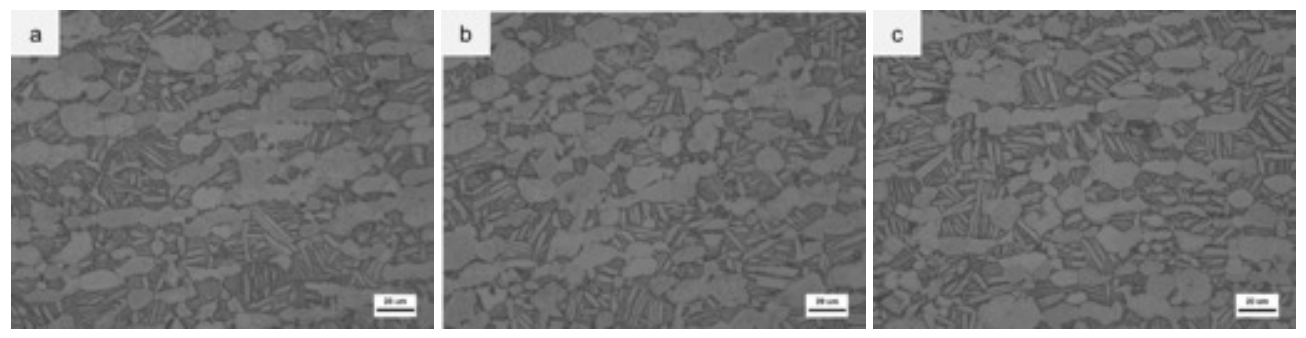

Fig 8. Microstructure after heated at $960^{\circ} \mathrm{C} / 1 \mathrm{~h}, \mathrm{AC}+730^{\circ} \mathrm{C} / 1 \mathrm{~h}, \mathrm{AC}$ and different ageing holding time heat treatment: (a) $550^{\circ} \mathrm{C} / 1 \mathrm{~h} / \mathrm{AC} ;(\mathrm{b})$ $550^{\circ} \mathrm{C} / 2 \mathrm{~h} / \mathrm{AC} ;$ (c) $550^{\circ} \mathrm{C} / 3 \mathrm{~h} / \mathrm{AC}$

\section{Conclusion}

(1) Due to the existence of processing orientation in conventional forging of Ti6Al4V Ti-alloy bar, there is a big difference in the ultrasonic velocity in the longitudinal and transverse direction, the longitudinal ultrasonic velocity decreased with the increase of forging deformation degree.

(2) The ultrasonic wave propagated faster in a phase compared to $\beta$ phase, thus the ultrasonic velocity increased as the volume fraction and thickness of a phase increased. 
(3) The processing orientation of microstructure is the main factor influencing the ultrasonic velocity. As the solution temperature increasing, the volume fraction of equiaxed $a_{p}$ decreased while that of lamellar $a_{s}$ increased, the processing orientation decreased but the ultrasonic velocity increased significantly. With the decrease of ageing temperature and the increase of ageing holding time, the longitudinal ultrasonic velocity increased. but the effect of ageing temperature on ultrasonic velocity is more effective than that of ageing holding time.

(4) The results would provide a guide to obtain a Ti-alloy bar with high-ultrasonic velocity through conventional forging combined with triple heat treatment process.

\section{References}

[1] Zhang Xiyan, Zhao Yongqing, Bai Chengguang. Titanium alloys and applications [M]. Beijing : Chemical industry press, 2005.

[2] Shi Yiwei. Analysis of standards and specifications on the ultrasonic inspection of titanium alloy bars [J]. Journal of Materials Enginerring, 6 (2002) 46-50.

[3] Su yong, Lin Weizheng. Measurements of material's acoustic velocity and attenuation by signal analysis [J]. Journal of Building Materials, 4 (2001) 65-69.

[4] Xu Zhidong, Fan Ziliang. A phenomenological explanation of the variation of elastic modulus with temperature for metallic materials [J]. Journal of Southwest Jiaotong University, 2 (1993) 87-92.

[5] Hu Zongshi. Relationship of clutter and microstructure in titanium ultrasonic inspection [J]. Titanium Industry Progress, 6 (2002) 31-34.

[6] Wang Guohong. Ultrosonic studies of phase transitions of titanium and titanium alloys [J]. Rare Metals Letters, 10 (2002) 8-9.

[7] Shan S L, Shen J Y, Wang X Z. Transformation textures in a $\alpha+\beta$ titanium alloy thin sheet [J]. Materials Science and Engineering: A, 360 (2002) 58-64.

[8] Zhang Zhihui, Wang Xizhe, Shang Shunli, Bai Kewu, Shen Jianyun. Influence of processing on elastic modulus for a titanium alloy with high strength and high elastic modulus. [J]. Chinese journal of Rare Metals, 25 (2001) 19-22.

[9] Z.C.Sun, F.X.Han, H.L.Wu, H. Yang. Tri-modal microstructure evolution of TA15 Ti-alloy under conventional forging combined with given subsequent heat treatment. [J]. Journal of Materials Processing Technology, 229 (2016) 72-81. 